\title{
PEMANFAATAN MODUL GSM DAN MODUL GPS PADA SISTEM KEAMANAN SEPEDA MOTOR MENGGUNAKAN SMARTPHONE BERBASIS ARDUINOUNO
}

\author{
Areta Sonya Rahajeng ${ }^{1}$, Muhardi ${ }^{2}$, Refni Wahyuni ${ }^{3}$, Yuda Irawan ${ }^{4}$ \\ 1, 2, 3, 4 Teknik Informatika, STMIK Hang Tuah Pekanbaru \\ aretasonyaaa@gmail.com ${ }^{1}$,muhardi.yudie@gmail.com ${ }^{2}$,refniabid@gmail.com ${ }^{3}$, \\ yudairawan89@gmail.com ${ }^{4}$
}

\begin{abstract}
To facilitate control of lights in a home with a remote control so they invented a system of utilization of GSM Module Based Arduino Uno For Home Lighting Remote Control. The whole tool is divided into several parts, which consist of a Mobile, GSM SIM 800L module, arduino uno microcontroller, relay module, and lights. This tool works when Mobile sends an SMS (Short Message Service) containing commands to GSM SIM 800L, from GSM SIM 800L then to the microcontroller to process commands, from the microcontroller then to the relay module that works as a substitute for a switch that functions to turn on or turn off the lights which are desired.
\end{abstract}

Keywords : Handphone, Arduino Uno, Module GSM SIM 800L, Relay

\begin{abstract}
Abstrak
Untuk mempermudah pengendalian lampu di sebuah rumah dengan kendali jarak jauh maka dibuatlah suatu sistem Pemanfaatan Module GSM Berbasis Arduino Uno Sebagai Kendali Lampu Rumah Jarak Jauh. Keseluruhan alat ini dibagi menjadi beberapa bagian yaitu terdiri atas Handphone, modul GSM SIM 800L, mikrokontroller arduino uno, modul relay, dan lampu. Alat ini bekerja saat Handphone mengirimkan suatu SMS ( Short Message Service) yang berisi perintah ke GSM SIM 800L, dari GSM SIM 800L kemudian ke mikrokontroler untuk memproses perintah, dari mikrokontroler kemudian ke modul relay yang bekerja sebagai pengganti saklar yang berfungsi untuk menyalakan atau memadamkan lampu yang di inginkan.
\end{abstract}

Kata Kunci : Handphone, Arduino Uno,Modul GSM SIM 800L, Relay 


\section{PENDAHULUAN}

Lampu merupakan komponen penting yang sangat bermanfaat untuk dapat membantu manusia dalam penerangan. Penggunaan penerangan di dalam rumah diharapkan sesuai dengan kebutuhan manusia. Aktivitas seseorang di luar rumah seperti liburan keluar kota atau urusan kerja yang mengharuskan seseorang meninggalkan rumah dalam keadaan kosong selama 24 jam atau lebih, akan menyebabkan seseorang mengalami kesulitan dalam pengontrolan lampu penerangan.

Saat rumah dalam keadaan kosong tak berpenghuni akibat pemilik rumah memiliki aktivitas di luar rumah, maka tidak ada yang menyalakan lampu saat malam hari dan mematikan lampu saat siang hari. Jika lampu dinyalakan terlebih dahulu sebelum seseorang berpergian dalam waktu 24 jam atau lebih, akibatnya menimbulkan pemborosan listrik sehingga membuat tagihan listrik naik dan memiliki dampak negatif lain seperti lampu mudah rusak atau mati karena menyala terus menerus.

Permasalahan ini dapat diatasi dengan memanfaatkan teknologi yang ada sekarang ini, salah satu diantaranya menggunakan module GSM ( Global System Mobile ) dan Mikrokontroler Arduino Uno sebagai alat pengendalian lampu jarak jauh. Peneliti ingin mengembangkan penelitian sebelumnya (Mohammad Jihaddudin,2018) yaitu pengendalian lampu menggunakan Mikrokontroler Arduino Uno dan modul Bluetooth yang jangkauan masih sangat terbatas dengan menggunakan modul GSM ( Global System Mobile) yang jangkauannya lebih luas dan dapat dikontrol dari jarak jauh. Penerapan teknologi ini dapat menjadi sebuah alternatif untuk pengendalian lampu rumah dari jarak jauh.

\section{LANDASAN TEORI}

Arduino adalah sebuah board mikrokontroller yang berbasis ATmega328P-PU. Arduino memiliki 14 pin input/output yang mana 6 pin dapat digunakan sebagai output PWM, 6 analog input, crystal osilator $16 \mathrm{MHz}$, koneksi USB, jack power, kepala ICSP, dan tombol reset. Arduino mampumensupport Mikrokontroller dan dapat dikoneksikan dengan komputer menggunakan kabel USB(Andi Adriansyah,dkk.2013).

Pada dasarnya Transformator terdiri dari dua kumparan yaitu kumparan primer dan kumparan sekunder. Dimana tegangan pada kumparan primer akan ditransformasikan atau diubah pada kumparan sekunder, yang besarnya tergantung dari masing-masing jumlah lilitan pada kedua kumparan tersebut (Suwitno.2016).

SIM800L adalah modul SIM yang digunakan pada penelitian ini.Modul SIM800L GSM/GPRS adalah bagian yang berfungsi untuk berkomunikasi antara pemantau utama dengan Handphonel Smartphone. AT Command adalah perintah yang dapat diberikan modem GSM/CDMA seperti untuk mengirim dan 
menerima data berbasis GSM/GPRS, atau mengirim dan menerima SMS. SIM800L GSM/GPRS dikendalikan melalui perintah AT. AT+Command adalah sebuah kumpulan perintah yang digabungkan dengan karakter lain setelah karakter „AT $\mathrm{AT}^{\mathrm{ee}}$ yang biasanya digunakan pada komunikasiserial. Dalam penelitian ini ATCommand digunakan untuk mengatur ataumemberi perintah modul GSM/CDMA. Perintah ATCommand dimulai dengankarakter "AT" atau "at" dan diakhiri dengan kode(0x0d) (Muradi,Dani Ratminto.2018)

Relay adalah saklar (Switch) yang dioperasikan secara listrik dan merupakan komponen Electromechanical(Elektromekanikal) yang terdiri dari 2 bagian utama yakni Elektromagnet (Coil) dan Mekanikal (seperangkat Kontak Saklar/Switch) (susanti,andri dan jauhari.2017).

Smartphone merupakan kombinasi fungsi dari perangkat komunikasi dan perangkat penunjang kebutuhan digital lifestyle dengan beberapa fitur multimedia dan organizer (widasari,dkk.2017).

Smartphone pertama diberi nama Simon yang dikembangkan oleh IBM pada tahun 1992 dan terpilih sebagai product of the year oleh COMDEX. Simon direlease pada tahun 1993 oleh BellSouth, selain fitur telephone dan SMS Simon dilengkapi dengan calendar, address book, world clock, notepad, e- mail, fax, dan games. Setelah itu banyak prodak sejenis yang dikeluarkan oleh berbagai vendor berbeda seperti Nokia. Sistem operasi yang digunakan pada smartphone berbedabeda tetapi yang paling banyak digunakan saat ini adalah sistem operasi yang berbasis Androiddari google.

\section{METODE PENELITIAN}

Dalam tahap ini peneliti menggunakan metode Waterfall, karena metode ini merupakan metode yang banyak digunakan oleh pengembang software. Inti dari metode ini adalah pengerjaan dari suatu sistem dilakukan secara berurutan atau secara linear. 


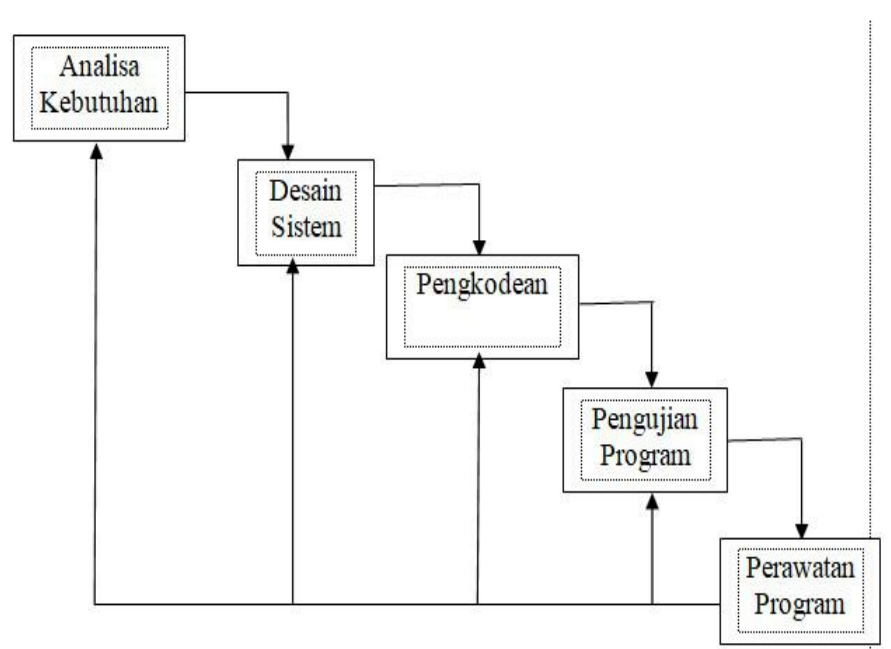

Gambar 2.1Waterfall Development Model

a. Analisis kebutuhan ( requirement definition )

Dalam tahap ini peneliti melakukan pengumpulan data secara lengkap dengan observasi, studi pustaka, serta wawancara yang akan menjadi acuan untuk membuat sistem sesuai kebutuhan.

b. Desain sistem ( system and software design )

Dalam memodelkan sistem peneliti menggunakan konsep Prosedural untuk menggambarkan desain dari sistem yang akan dibangun.

\section{c. Pengkodean ( implementation )}

Desain program pada tahapan sebelumnya diterjemahkan dalam bentuk kode-kode dengan menggunakan bahasa pemrograman. Dalam sistem ini bahasa pemrograman yang dipakai adalah bahasa $\mathrm{C}++$.

\section{d. Pengujian( integration )}

Dalam tahap ini dilakukan penggabungan modul - modul yang sudah dibuat dan dilakukan pengujian untuk mengetahui apakah sistem yang telah dibangun sesuai dengan desain dan apakah masih ada kesalahan atau tidak. Pengujian menggunakan Black Box yaitu pengujian yang dilakukan langsung oleh User.

\section{e. Perawatan ( maintenance )}

Dalam tahap terakhir di model waterfall ini sistem yang sudah dijalankan harus dilakukan pemeliharaan. Pemeliharaan juga termasuk memperbaiki kesalahan yang tidak dapat ditemukan dalam tahap sebelumnya.

\section{ANALISIS DAN PERANCANGAN}

Sistem pengendalian lampu rumah selama ini masih menggunakan saklar manual. Dimana pada saat akan menyalakan dan memadamkan lampu seseorang harus berjalan menuju ruangan atau tempat control lampu untuk menekan saklar lampu tersebut agar hidup atau padam. Sehingga disaat pemilik rumah keluar 
untuk waktu yang lama maka pengendalian terhadap lampu di rumah tidak dapat dilakukan.

\section{Analisa Kebutuhan Sistem}

Analisis kebutuhan sistem dilakukan untuk mengetahui spesifikasi dari kebutuhan aplikasi yang akan dibangun. Pada tahap ini akan membahas mengenai perangkat keras dan perangkat lunak yang digunakan dalam pembuatan Pemanfaatan Module GSM Berbasis Arduino Uno sebagai Kendali Lampu Rumah Jarak jauh.

\section{Analisa Proses}

Analisis proses adalah menganalisa proses dari pertama kali perancangan alat sampai jadi prototype pemanfaatan module GSM berbasis arduino uno sebagai kendali lampu jarak jauh.

\section{Perancangan Perangkat Keras}

Perancangan perangkat keras merupakan rancangan atau rangkaian dari alat yang digunakan untuk membangun prototipe Pemanfaatan module GSM berbasis arduino uno sebagai kendali lampu jarak jauh.

1) Rangkaian Power Supply

Rangkaian Power Supply merupakan rangkaian elektronik yang berfungsi untuk mengubah tegangan dari AC (Alternating Current) Arus bolak-balik menjadi tegangan DC (Direct Current) Arus searah.

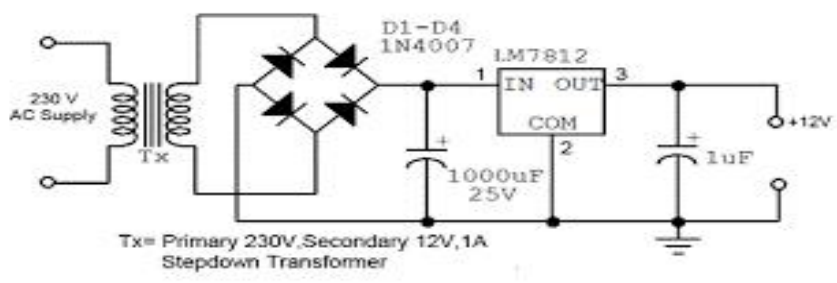

Gambar 3.1 Rangkaian Power Supply

2) Rangkaian Mikrokontroler Arduino Uno dengan Modul GSM SIM $800 L$

SIM $800 \mathrm{~L}$ ini berfungsi sebagai media penghubung antara Smartphone atau Handphonedan Mikrokontroler Arduino Uno agar pengendalian lampu dapat di kontrol dengan Smartphone melalui pesan singkat atau Short Message Service ( $S M S$ ). 


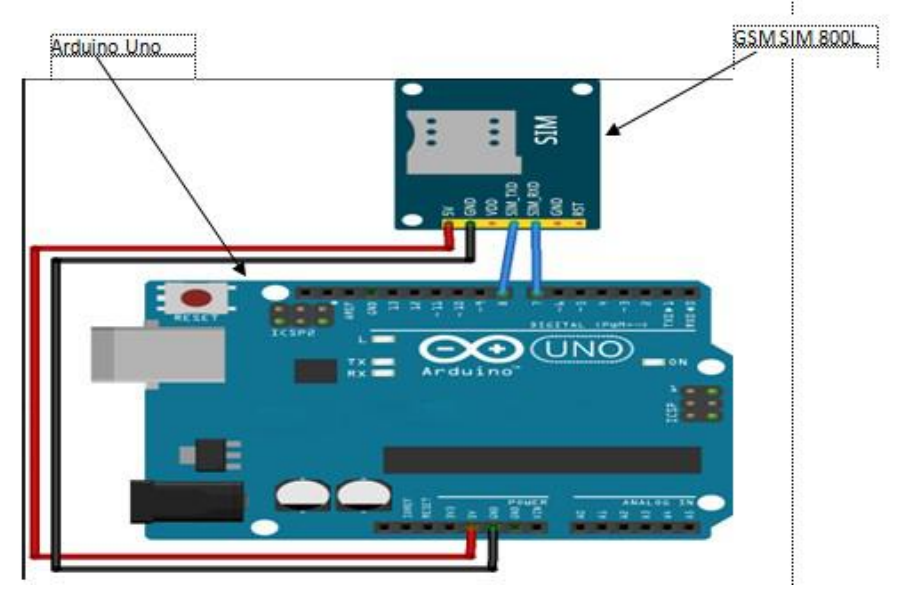

Gambar 3.2 Rangkaian Mikrokontroler Arduino Uno dengan SIM800L

3) Rangkaian Mikrokontroler Arduino Uno dengan Module Relay 4 chanel Rangkaian module relay dengan Mikrokontroler Arduino Uno digunakan untuk menghubungkan atau memutuskan arus listrik kepada lampu yang terhubung. Rangkaian ini dirancang sesuai program mikrokontroler arduino, dimana terdapat sinyal kontrol dari mikrokontroler arduino.

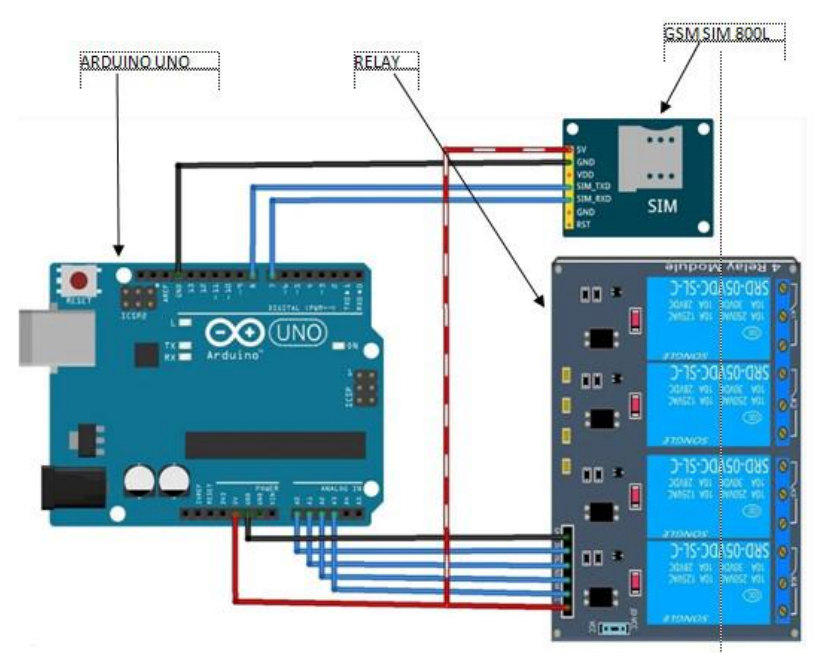

Gambar 3.3 Rangkaian Mikrokontroler Arduino Uno dengan Module Relay 4 chanel

a) Rangkaian keseluruhan konfigurasi perangkat keras

Gambar dibawah ini merupakan rangkaian keseluruhan alat Sistem Pemanfaatan Modul GSM berbasis arduino uno sebagai kendali lampu jarak jauh. 


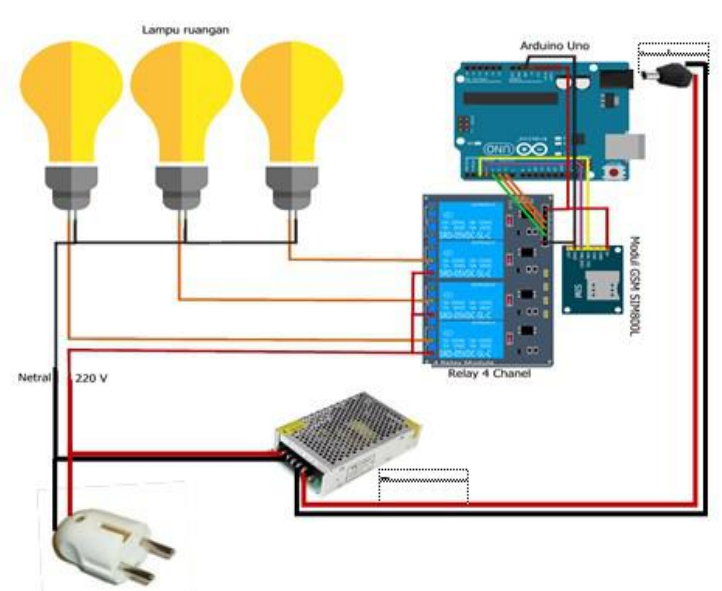

Gambar 3.4 Rangkaian keseluruhan konfigurasi hardware

b) Perancangan perangkat lunak (Software)

Pada sistem ini perancangan perangkat lunak yaitu perancangan perangkat lunak pada modul pengendali utama (Papan Mikrokontroler Arduino Uno).

\subsection{Perancangan Sistem Secara Umum}

\subsubsection{Use Case Diagram}

Perancangan use casediagram dapat menggambarkan kebutuhan fungsional dari aplikasi yang dibuat. Dengan dirancangnya use case diagram ini, maka dapat dideskripsikan interaksi antara User dan Sistem pemanfaatan modul GSM berbasis arduino uno sebagai kendali lampu jarak jauh.

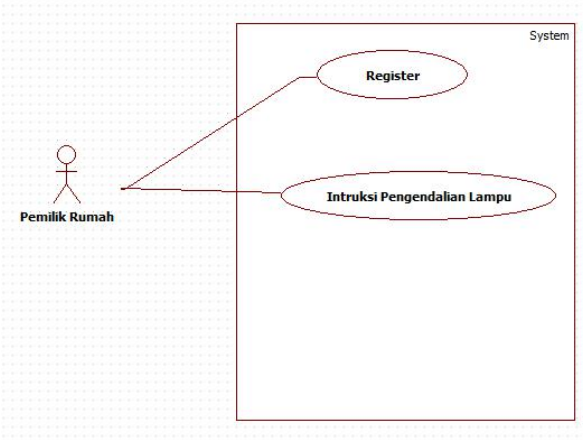

Gambar 3.6 Use CaseDiagram

\section{IMPLEMENTASI DAN PEMBAHASAN}

\subsection{Implementasi}

Implementasi merupakan salah satu tahap dalam pengembangan sistem, dimana tahap ini merupakan tahap meletakkan sistem pemanfaatan module GSM berbasis Arduino Uno sebagai kendali lampu rumah supaya siap untuk dioprasikan dan dapat dipandang sebagai usaha untuk mewujudkan sistem yang telah dirancang. 


\section{Implementasi perangkat pengendalian lampu rumah}

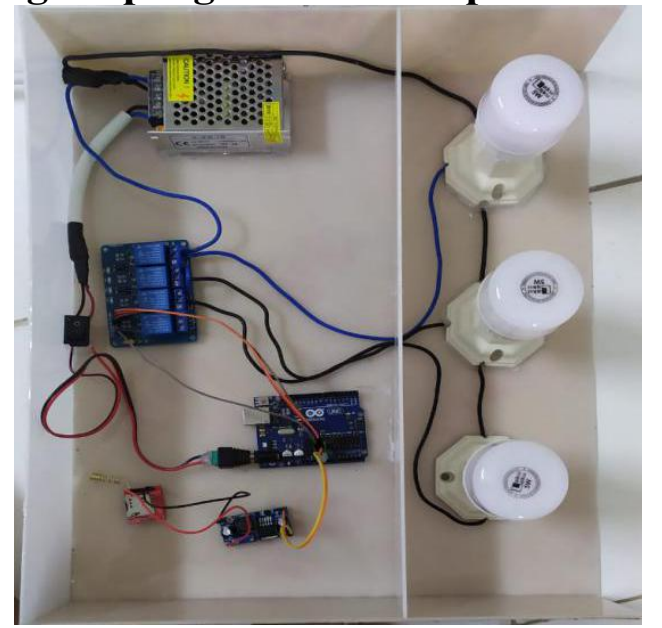

Gambar 4. 1 Implementasi perangkat keras pengendalian lampu

\section{Pengujian Sistem}

Pengujian sistem dari Handphone, Module GSM SIM 800 serta Arduino Uno pada sistem pemanfaatan module GSM berbasis Arduino Uno sebagai kendali lampu rumah jarak jauh dapat dilakukan dengan langkah-langkah sebagai berikut :

1. Hubungkan sumber arus listrik PLN ke rangkaian perangkat keras pengendalian lampu

2. Setelah itu sistem pemanfaatan module GSM berbasis Arduino Uno sebagai kendali lampu rumah jarak jauh akan menyala seperti perangkatperangkat pendukungnya yaitu Arduino Uno, Module GSM SIM 800, Power Supply, serta rangkaian relay-relay nya.

3. Lalu persiapkan Handphone serta buka Short Message Service ( $S M S$ ) yang nantinya digunakan sebagai Remote kendali lampu rumah.

4. selanjutnya kita lakukan pengujian SMS (Short Message Service) untuk melakukan perintah menghidupkan atau mematikan lampu rumah apakah berjalan dengan baik atau tidak.

A. Perintah Short Message Service ( SMS ) untuk menghidupkan lampu 1

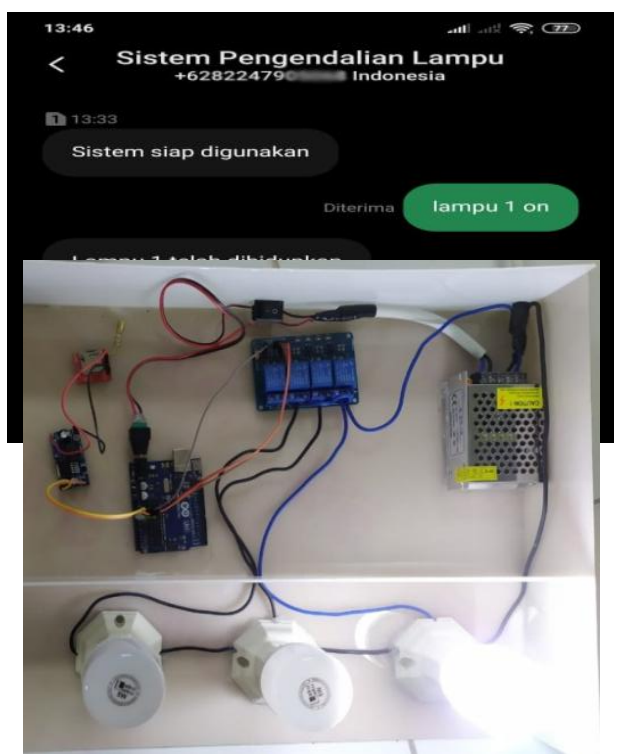


Gambar 4. 2 Uji perintah lampu 1

B. Perintah Short Message Service ( SMS ) untuk menghidupkan lampu 2

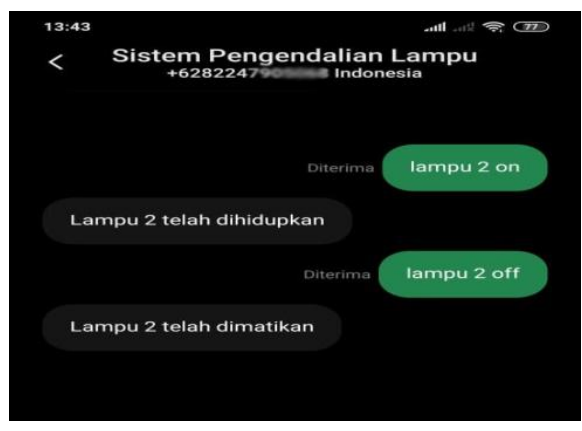

Gambar 5. 3 Uji perintah lampu 2

C. Perintah Short Message Service ( SMS ) untuk menghidupkan lampu 3

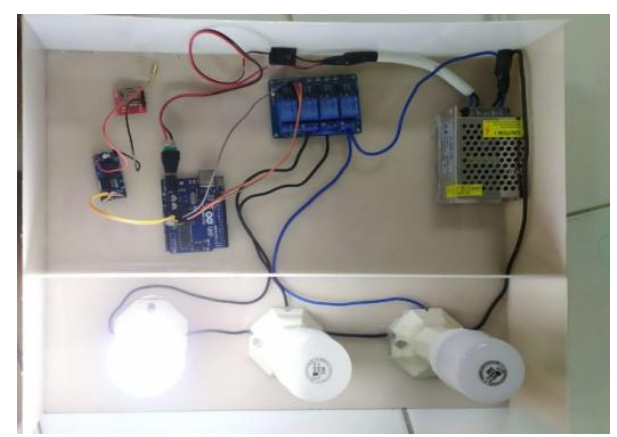

Gambar 5. 4 Uji perintah lampu 3

D. Perintah Short Message Service ( SMS ) untuk menghidupkan semua lampu
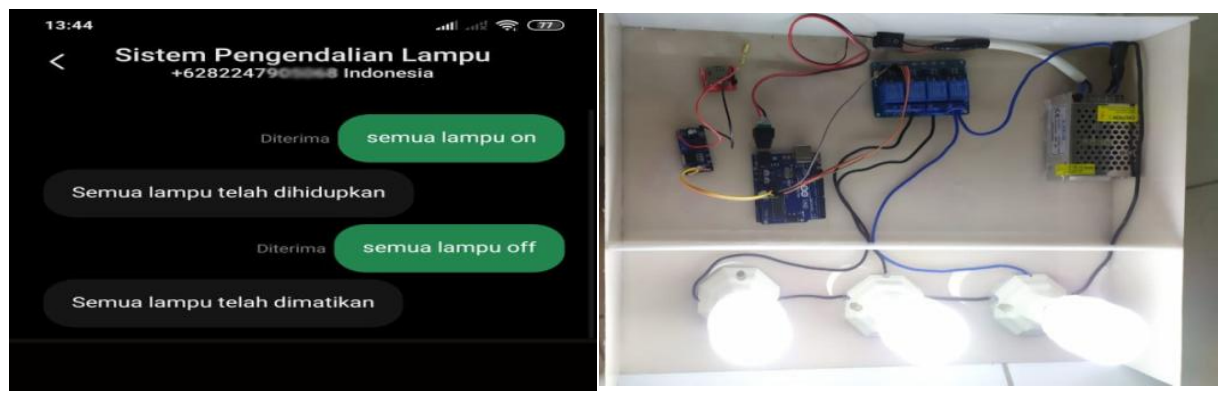

Gambar 4. 4 Uji Perintah Semua Lampu 


\section{KESIMPULAN DAN SARAN}

\section{Kesimpulan}

Berdasar hasil analisis, perancangan dan implementasi yang telah dilakukan. Maka dapat diambil beberapa kesimpulan diantaranya Perancangan sistem pemanfaatan module GSM berbasis Arduino Uno sebagai kendali lampu rumah jarak jauh, dimana Handphone sebagai pengendali, Mikrokontroler Arduino Uno sebagai pemroses data, Modul GSM SIM 800Lsebagai media komunikasi dan Relay sebagai Switch/Saklardapat bekerja dan berfungsi dengan baik sehingga lebih efisien dalam menyalakan dan memadamkan lampu. Sistem pengendalian lampu ini dapat memudahkan pemilik rumah saat beraktifitas diluar rumah, sehingga pemilik rumah bisa menghidupkan atau memadamkan lampu dari jarak jauh. Dengan menggunakan sistem pengendalian lampu ini dapat mengurangi pemborosan listrik karena lupa mematikan lampu.

\section{Saran}

Adapun saran bagi peneliti yang ingin mengembangkan penelitian ini, antara lain Untuk peneliti berikutnya dapat menggunakan media penghubung jarak jauh lainnya, yaitu menggunakan internet. Peneliti berikutnya agar mengembangkan tidak hanya pengendalian lampu saja, tetapi bisa di aplikasi kan ke alat yang lain, yaitu pengendalian pintu rumah, alat elektronik lainya seperti kipas angin,tv maupun AC serta alat elektronik lainnya.

\section{DAFTAR PUSTAKA}

[1] Adriansyah, Andi, dkk. September 2013. "Rancang Bangun Prototipe Elevator Menggunakan Microcontroller Arduino Atmega 328P”. Jurnal Teknik Elektro Universitas Mercu Buana (ISSN) Vol 4 No 32013.

[2] Muradi, Dani Ratminto., 2018, "Rancang Bangun Sistem Pemantau Keamanan Terhadap Pencurian Pada Lumbung Padi Menggunakan SMS Gateway Berbasis ATMEGA 32 ", Skripsi, Jurusan Teknik Elektronika, Universitas Muhammadiyah Malang.

[3] Irawan, Y. (2017). Sistem Pendukung Keputusan Untuk Penilaian Prestasi Belajar Siswa Pada Sekolah Dasar Negeri 167 Pekanbaru Dengan Metode Analytical Hierarchy Process (AHP). Jurnal Ilmu Komputer, 6(2), 85-90.

[4] Hussein, O. S., Wahyuni, R., \& Mukhtar, H. (2018). Sistem informasi deteksi kehadiran dan media penyampaian pengumuman dosen dengan menggunakan teknik pengenalan QR code. Rabit: Jurnal Teknologi dan Sistem Informasi Univrab, 3(2), 85-92.

[5] Suwitno. Februari 2016. "Mendisain Rangkaian Power Supply Pada Rancang Bangun Miniatur Pintu Garis Otomatis". Jurnal Of Electrical Technology (ISSN) Vol 1 No 12016.

[6] Irawan, Y. (2019). Sistem Informasi Pemasaran Busana Syar'i dengan Penerapan Customer Relationship Management (CRM) Berbasis Web. INTECOMS: Journal of Information Technology and Computer Science, 2(1), 1-9. https://doi.org/https://doi.org/10.31539/intecoms.v2i1.629 
[7] Widasari, Edita Rosana dkk. 2017. "Perancangan Pengendali Rumah Menggunakan Smartphone Android dengan Konektivitas Bluetooth”. Jurnal Pengembangan Teknologi Informasi dan Komputer Universitas Brawijaya,Malang Vol.1 No.5 2017. e-ISSN : 2548-964X.

[8] Irawan, Y., Rahmalisa, U., Wahyuni, R., \& Devis, Y. (2019). Sistem Informasi Penjualan Furniture Berbasis Web Pada CV. Satria Hendra Jaya Pekanbaru. JTIM: Jurnal Teknologi Informasi dan Multimedia, 1(2), 150159. 